\title{
Of Grief and Well-being: Competing Conceptions of Restorative Ritualization
}

\author{
Jenny Hockey , Leonie Kellaher \& David Prendergast
}

To cite this article: Jenny Hockey , Leonie Kellaher \& David Prendergast (2007) Of Grief and Wellbeing: Competing Conceptions of Restorative Ritualization, Anthropology \& Medicine, 14:1, 1-14, DOI: $10.1080 / 13648470601106079$

To link to this article: https://doi.org/10.1080/13648470601106079

册 Published online: 21 Feb 2007.

Submit your article to this journal $\pi$

Џll Article views: 280

Q View related articles $₫$

4 Citing articles: 9 View citing articles 


\section{Of Grief and Well-being: Competing Conceptions of Restorative Ritualization}

\section{Jenny Hockey, Leonie Kellaher and David Prendergast}

Informants' accounts of what they did with ashes they had chosen to remove from UK crematoria described disposal and memorialization strategies that have implications for anthropological understanding of issues of well-being, and the generation of new ritual practices. Here we aim to explore informants' conceptions of how well-being might be restored after a bereavement and how these were being put into practice. Data were gathered as part of an Economic and Social Research Council (ESRC) funded project, which used qualitative interviewing and focus groups among professionals involved with independent ash disposal; and individuals who had removed the ashes of relative or friend from a crematorium. Barking and Dagenham, Nottingham, Sunderland and Glasgow were our field sites. Analysis involved recognizing these data as 'motivated narratives' (Bury 2001) that, for example, extended informants' relationships with the dead, as well as reflecting tensions between professionals' imperatives to complete work with a client and their commitment to offering individual choice and support during their ongoing relationship with the dead. Such findings highlight the contested nature of contemporary conceptions of restorative ritual, with tensions existing between the meta-narratives of individual choice and professional expertise; between different individuals' 'choices'; and between the event of a death ritual and the process of ritualization. These findings contribute a nuanced account of the diversity of discursive practices through which the individuals, both 'lay' and professional, involved in a particular death, might understand how well-being can be restored.

The grief discussed in this paper was represented in narratives generated by immediate relatives and friends of the deceased during interviews which we describe below. In juxtaposition with these representations, tentative claims were also being made- that something had eventually been achieved. All our informants had taken,

Correspondence to: Jenny Hockey, Department of Sociological Studies, University of Sheffield, Elmfield, Northumberland Road, Sheffield S10 2TU, UK. Tel.: 0114-2226461; Email: j.hockey@shef.ac.uk 
or been charged with responsibility for disposing of the deceased's ash remains at a site other than the crematorium, a responsibility previously controlled and managed by institutions and professionals. Most informants had not appreciated what would be entailed, immediately or longer term, in making this choice. Alec Roth, ${ }^{1}$ for example, a Glasgow humanist officiant in his 50s, described disposing of the ashes of an old friend: 'We came to dealing with the ashes and I really honestly didn't know what to do at all 'cos Tim had left no requests, he had no next of kin, he had no family of any kind, they had all died off.' Tim had been a prominent member of the gay community on a Scottish island, as Alec describes: 'And Tim talked about the palm trees and, in the dark in the wartime and all things that he did out there, so I went out eventually and sprinkled his ashes privately, 'cos I tried to get permission, I approached the District Council down there and they refused.' All this left Alec feeling 'very illicit and very dodgy' and it was only upon reflection that he discovered some coherence to this choice: 'But then I thought well what he did round these trees was fairly illicit and dodgy, so it probably was quite appropriate. He probably would approve.'

Such decision making was described by many informants as having somehow made them feel 'better'. However, they also sought re-assurance that they had done the 'right and proper' thing (Hockey et al. 2005). These data can be approached through the concept of 'well-being' and allow us to explore its complex, potentially competing dimensions. For example, in transcending the purely private realm, do our informants' practices reflect popular notions of ritual? As we go on to show, their 'lay' decision making could be contested by death-care professionals. When we problematize the concept of 'ritual', however, it becomes evident that lay and professional participants in the production of 'ritual' are not necessarily engaged in the same spatio-temporal domain. As we argue, there appears to be a distinction between a ritual event and the process of ritualization.

What we ask therefore is:

- How those who remove ashes from the public arena of the crematorium might implicitly envisage their choice contributing to the recovery of well-being?

- Whether bereaved people in this situation anticipate a more accelerated return to well-being than that resulting from the practices of municipal or religious institutions?

- To what extent do the initiatives of bereaved people align with traditional ritual practice? Can we identify their actions as a ritual event or as part of a process of ritualization?

\section{The Study ${ }^{2}$}

Whereas only one in 10 sets of ashes were removed from a crematorium by family or friends in 1970, by 2004 over 56 per cent of all cremated remains were being removed for disposal elsewhere (Kellaher et al. 2004). The treatment of cremated ashes, as increasingly practiced in this country, therefore renders the dead potentially mobile. Unlike the fixed location of whole body burial, ashes can be distributed according to the wishes of survivors. The management of death therefore appears to be cut loose 


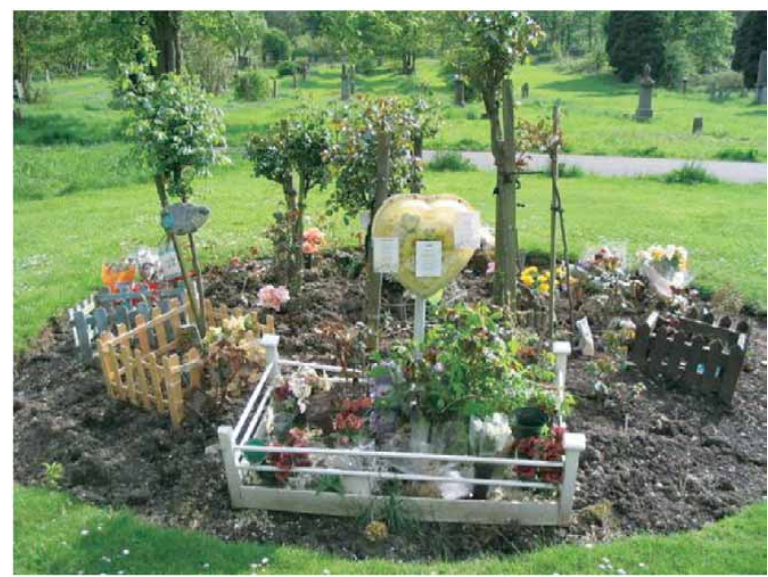

Figure 1 Memorialization at Cemetery Ash Disposal Site.

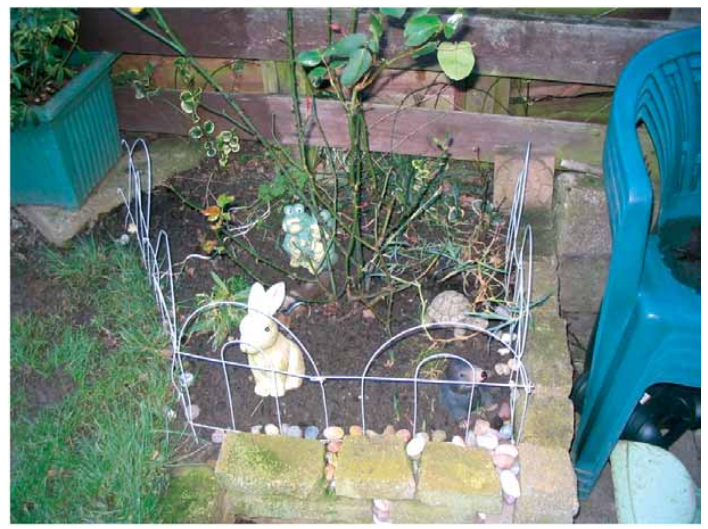

Figure 2 Ash Shrine in Back Garden.

from stable locations, such as the church and municipal settings. Our study has explored this trend via data gathered in the four sites surveyed by Davies and Shaw (1995): Barking and Dagenham, Nottingham, Sunderland and Glasgow. At each site, in-depth interviews and focus groups, with a minimum sample of seven professionals, give a broad picture of local practices. They included funeral directors, clergy, hospital midwives, social workers, bereavement counsellors and crematorium managers. Fifteen bereaved people who had removed a relative or friend's ashes from a crematorium for disposal elsewhere were interviewed in each of the four locations, generating around 60 bereaved case studies and 30 professionals.

Most informants were close kin of the deceased, with just three related through friendship. Women featured rather more than men since many of the bereaved spouses were surviving widows ( 14 widows, 5 widowers). Amongst those who had disposed of a parent's ashes, women in later mid-life who had responsibility for a father's ashes predominated (14 daughters/fathers; 7 daughters/mothers; 


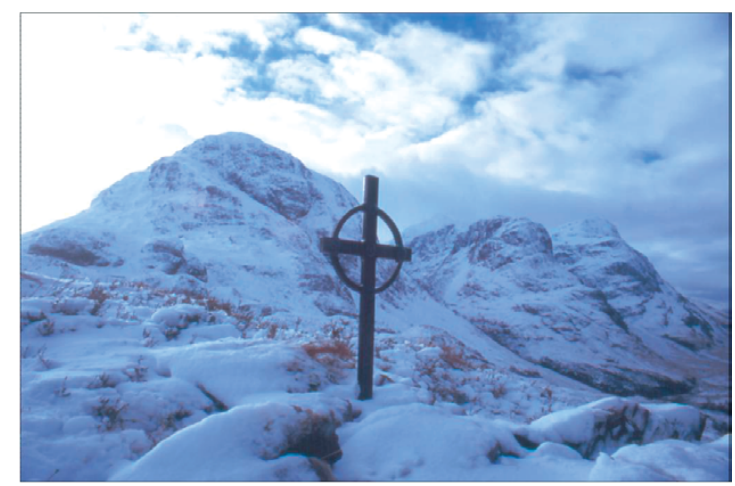

Figure 3 Marking of Ash Disposal Site.

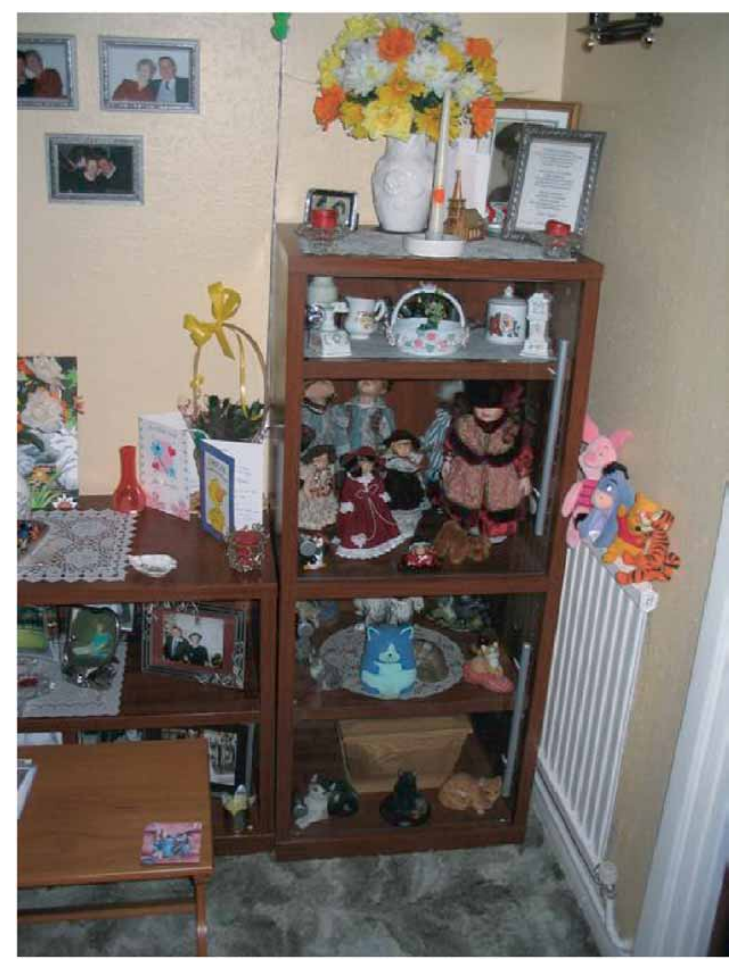

Figure 4 Interim Disposal at the Bottom of Domestic Display Cabinet.

4 sons/fathers; 6 sons/mothers). Regardless of gender, however, informants expressed a concern for the deceased that focused on materialities such as the warmth, dryness, safety and companionship they were affording the dead. In his 70s, Geoffrey Lunn from Sunderland, for example, said of scattering the ashes of his older sea-faring brother at sea: 'He used to be at sea so he'd be quite happy where he is'. Marilyn Mason, a Sunderland teacher in her 40s described scattering the ashes of Bertha, her 
mother-in-law on her child's grave because 'We didn't want her to be lonely.' She said her relationship with Bertha had been 'close', adding 'I'd actually had her longer than I'd had my own mam, 'cos my mam died when I was 27.' Prior to her death, Bertha had re-located to institutional accommodation, chosen by Marilyn and her husband because it was near their home. Narratives of both parental and spousal deaths frequently covered similar issues of co-residence, proximity, duty and affect. The Carters, a Nottingham couple in their 60s, described disposing of the ashes of their 29-year-old son in 'a nice little casket with the ashes, which was buried into the grave at Kidston, we had to get official permission'. They explained their choice as follows:

We were brought up at Kidston, got married at Kidston, that's where we met. It's our second home, and your father's... neither of us wanted him to be on his own if you like, his remains, so that's why we put him at Kidston, and he liked Kidston, my parents lived there, although he never knew his grandfather but he was very fond of my mother, so and that's where I'm going and that's where Billy wants to go.

We develop these points through an extended case study that demonstrates the interaction of age and relatedness: A middle-aged daughter provided daily care for her widowed father and then transposed this idiom of care to the treatment of his ashes. Circumstances surrounding the deaths described in our data generate variations that a single case study cannot encompass-from the sudden, though not always unexpected, through to chronic conditions that pre-occupy a spouse or an adult child for months, if not years. In addition the structure and disposition of each surviving network is quite particular. Nonetheless, the case selected illustrates an important post-mortem tendency towards securing well-being through choices that reproduce the idiom of relatedness between the deceased and their survivors during life. And as we observed across this data set, many survivors persist with familiar templates for care.

\section{On Well-being}

The term 'well-being', describing a state that bereaved people may seek through engagement with cremated remains, can be contrasted with a state of grief stimulated by loss. Both terms have been a focus within disciplines other than anthropology: Medicine and psychiatry, social psychology, philosophy and theology. In subsidiary fields such as the social indicators movement and counselling, these definitions have been further refined. Well-being, described in the WHO 1946 definition, as 'a state of complete physical, mental and social well-being', has since been conceptualized as consequent upon the interaction of segmented domains, judged subjectively or objectively, as resting on aspects of health, economic, social and personal resources etc. (e.g., Andrews \& Withey 1976). In addition, the balance of positive and negative affects or factors prevailing at any one time, or over an extended period has been used to evaluate well-being (see for example, Bradburn 1969).

Philosophical traditions, for example, infer states tangential to well-being: Goodness, happiness and pleasure. Utilitarian arguments for the principle of the greatest good encompass the case of people, including those bereaved of close kin, 
acting to maximize personal well-being (West 2004). Some would say that bereaved people may not be disposed towards rationality, yet they could nonetheless be expected to edge towards comforting actions, rather than the converse. Although not the cost-benefit 'calculation' that a fully utilitarian approach entails, this is likely to be a highly complex effort, given tensions between imperatives to 'recover' and commitments to the memory of the deceased.

If utilitarianism privileges achieving happiness, other perspectives consider how happiness might be achieved. Not eschewing rationality, Aristotelian accounts of happiness see it as the outcome of activity directed by what is good and proper. And existentialist approaches to mourning would not reduce it so starkly to restoration of pleasure or avoidance of pain, but would see bereaved people as unknowing, in any rationally directed sense, about attaining happiness, yet somehow managing the intensity of loss. The notion of well-being as an oscillating set of processes, balanced between positive and negative feelings (Bradburn 1969), might however, best fit our data. These philosophical traditions encompass the individual and collective human condition, in contrast with anthropological approaches, which have tended to privilege the cultural and collective over the individual.

From Hertz (1907/1960), to James Watson (1982), to Bloch and Parry (1982), anthropologists have asked how societies sustain themselves despite the deaths of their members. In addition, this literature often links the notion of 'well-being' with the concept of restoration and offers broad-based conceptions of the term; for example, the well-being of the natural environment which can include 19th-century concerns about dangerous miasmas emanating from urban graves overflowing with rotting working class bodies (Francis et al. 2005), through to 21st-century worries about a global environment polluted by emissions from cremated corpses (Hansard 2004). In addition, the well-being of the material environment can include the need to sequester the dead within bounded space at the peripheries of settlements (Hallam \& Hockey 2001). Socially, there is the question of how the well-being of communities, families and individuals_-both dead and alive-might be sustained, despite the unpredictability of death.

\section{Interpreting Testimonies}

In interpreting our data to consider well-being and ritualization we draw on these literatures, particularly the debated notion of intentionality or agency and its links with 'rational' decision-making. We begin by recognizing the data's status as a narrative reconstruction of previous practice, drawing on Bury's (2001) work in relation to illness and its potential to rupture life scripts and social identities. He argues that illness narratives are not simply accounts that transcend reductionist medical diagnoses. Although they may indeed be holistic, incorporating the personal, social, emotional and medical dimensions of illness, they cannot be seen as transparent, subjective accounts of experience. Rather, Bury (2001) argues, they are strategic, enabling a stigmatized or ruptured identity to be repaired — and suffering to be accommodated without risk to ontological security. 
What bereaved people said during their interviews can similarly be seen as forms of strategic narrative reconstruction. Drawing on newly developed lay knowledge bases, or tacitly evoking traditional beliefs and practices within the framework of new disposal strategies (Kellaher et al. 2004), informants described how they confronted the rupture introduced into their lives by bereavement. Not only were the effects of their loss detailed, but also the ways in which these had been addressed. When Ellen Longman, a Nottingham woman in her 60s, described the emotional impact of her adult daughter's sudden death from diabetes, she said 'I mean the grief was so raw at first I personally didn't know I would survive her death.' Yet she and her husband found comfort through visiting the local country park where they scattered the daughter's ashes. Explaining their choice, Ellen drew on her memories of the past: 'We were on a country walk and she [her daughter] was striding out, she was fairly fit at the time and she just suddenly out of the blue turned to me and said "when I'm dead I want to be buried under a tree" and my response was "well that's a lovely idea".' Reflecting on their now frequent visits to the site, David, her husband mused, 'I think my feeling was... we interred her ashes in a place which had a calming peaceful effect.'

Describing narrative's reconstructive aspect, Bury uses the concept of 'vocabularies of motive' (2001, p. 282) and indeed we found that some individuals saw their interview as part of their memorializing strategy. As we discuss below, therefore, our research activities can be seen as part of an informant's 'process of ritualization'. For example, in that recruitment used broad sweep methods such as local newspaper advertising, snowballing and using death-care professionals as gatekeepers, informants were mainly self-selected. Unusually in research on sensitive topics, some interviewees wished to be identified-along with the deceased-a device that bridged the gap between them. Bury also cites Riessman's injunction that the social scientist should explore 'why the story was told that way?' (2001, p. 281) and if we ask that question of our data then issues of guilt and restoration become apparent. Thus, the interview narrative allowed the bereaved person to re-represent him/herself and their actions as moral, their responses to suffering as successful.

Although both Aristotelian and existentialist conceptions of well-being might eschew the Utilitarian notion of rational choice at a time of emotional turbulence, as a form of narrative reconstruction the research interview allows informants to generate a coherent account of their strategic choices when taking on or charged with responsibility for cremated remains. 'Rationality' is therefore flagged in such accounts and we can understand this in terms of Bennett and Bennett's (2000) discussion of interviewing widows to gather accounts of experiencing the presence of the dead. These authors argue that '[e]specially with strangers, or in the context of a scientific survey, they [widows] may prefer to opt into the materialist discourse and describe their experiences in the language of illusion'-this rather than more 'supernaturalist' accounts of what transpired (Bennett \& Bennett 2000, p. 154). In that our interviews can be seen as the co-production of both researcher and researched (Clifford \& Marcus 1986), it is also important to recognize that although interviews were designed to allow informants to tell whatever story they chose, the research process is nonetheless motivated by a search for data that will support 
intellectually coherent analyses. This dimension of the process of co-producing data therefore needs to be recognized when addressing the question 'why was the story told that way?' To further complicate the interpretation of this material, whereas illness narratives may distance the individual from his or her condition, bereavement narratives can reflect a tension between apparently coming to terms with a loss through strategically chosen actions, and an associated rejection of the dead implied by returning to a state of emotional well-being.

If Bury (2001) argues for the motivated qualities of any narrative then we can begin to ask how informants' accounts of independent ash disposal might be oriented towards the exercise of agency in managing a changed relationship with the dead. As Walter (1996) argued, rather than emotional outpouring, a biographical response to grief can allow a death to be 'come to terms with', and the deceased to be integrated into survivors' lives. His idea helped stimulate a paradigm shift in bereavement theory, problematizing the notion that 'continuing bonds' between the living and the dead are pathological (Klass et al. 1996). As shown in the narrative data presented here, informants represent agency being exercised precisely in nurturing an ongoing relationship with the dead. And as our case study reveals, such narratives affirm the moral status of the bereaved person and point up the relational nature of well-being.

\section{Core Narratives}

Bury's (2001) analysis of narrative reconstruction involves the identification of an interview's core narratives. These 'reveal connections between the lay person's experiences and deeper cultural levels of meaning attached to suffering' (2001, p. 263). Given our focus on the public appropriation of decisions previously made by professionals, the concept of 'choice' emerged as a key cultural reference in the narratives that informants generated in response to our enquiry. As Joan Bakewell argued in the Guardian newspaper: 'Burials, scattered ashes, memorials ... the new mantra of consumer choice now even applies to death' (2004). Describing new disposal options available for 'an overcrowded world', Bakewell infers that personal rather than institutional influences, consumption rather than religion, shape reactions to death. This, she suggests, 'open(s) up all sorts of new and satisfying opportunities, choices that often help in the business of bereavement'.

Two related themes are articulated by our informants: The notion that choice is a positively value-laden concept in the west; and that the right choice can help with 'the business of bereavement' and the recovery of 'well-being'. As Bakewell (2004) notes, 'It's typical of our highly individual age that we don't settle for accepted norms even in death.' Nonetheless, Craib (1994) argues that the 20th century also saw a proliferation of experts who sought to bring bereavement within a manageable normality, whose interventions are believed to return well-being. What we argue, therefore, is that the goal of bringing bereavement within a manageable normality, can create or expose divisions between professionals and bereaved people, and indeed between family members. In particular, we argue that-for both professionals and lay bereaved people_-there is a tension between a commitment to 'personal choice' 
and a persistent belief in professionally authenticated narratives of appropriate behaviour. In other words, between improvisation and formally encoded principles. Walter (1994) too, notes the tension between a modernist reliance on experts and a neo-modern commitment to the authority of the self as a source of appropriate knowledge at the time of death. In this connection, the emphasis on 'letting go' within an earlier therapeutic literature on bereavement has been questioned, particularly by older widowed people and bereaved parents - and their voices underpin the subsequent commitment to 'continuing bonds' with the dead (Klass et al. 1996). Yet despite changes in personal beliefs and practice, earlier therapeutic beliefs live on in what Walter (1999) calls the 'clinical lore' of local level death-care practitioners.

If we ask 'why was the story told that way?' when examining data from lay and professional interviewees, we need to consider whether, for example, bereavement counsellors were simultaneously trying to demonstrate that their training was up-to-date when describing the need to support personal choice. The 'clinical lore' on which they drew when supporting a client might equally reflect earlier imperatives to 'let go' of the dead. Similarly, when cemetery or crematorium managers stress the importance of personal choice, are they influenced by the demands of 'Best Practice' with its cost-benefit calculus, which recognizes them as competent insofar as they demonstrate the availability of 'choice'? Equally, tension is stimulated by the insistence that cemeteries be maintained as historic, public landscapes, with restriction on individual choice and preference.

Bringing this diversity of agendas to the fostering of choice is one area of implicit contestation. Some professionals may acquire unmanageable workloads if bereaved people mourn the dead in ways that involve continued demands upon their services. If a stage model of grief with its trajectory from numbness to acceptance (Parkes 1972) remains core to many practitioner narratives, this may be simply a pragmatic solution to the demands of their job. Data from one funeral director exemplifies this questioning of on-going relationships with the dead. He asked, rhetorically, whether the retention of ashes by survivors 'help(ed) or hinder(ed) the bereavement cycle?' Confidently, he went on: 'I think it hinders it actually ... they don't quite get over the last hurdle, that last hurdle of scattering the ashes or placing the ashes into the ground, and walking away... it's the final goodbye and they can't quite do that. The ashes are still there and they can't quite get over that last hurdle.' He saw older people experiencing particular difficulties here: 'They [older clients] want the ashes back to help them,' he said, 'but it may help them in the short term but in the long term, I'm not... They're not focused like, you know, they rely on it too much.'

In discussing the relationship between modernist professional expertise such as this and the authority of the self in making choices at the time of death, Walter argues that 'the individual self can die his or her own way, but only in company with others' (1994, p. 189). When we consider the experiences of grief and loss, we find similar potential for contested conceptions of the ways in which ritual practice might restore well-being and this raises the question of whether or not lay and professional ritual participants are engaged in the same spatio-temporal domain. 


\section{From Ritual Event to Ritual Process}

Current anthropological thinking contests notions of ritual as a fixed structure and Rosaldo (1989) argues that funerals that seem to reveal culturally specific systems of order, displaying both a clear internal structure and a discernible match with other aspects of cultural and social life, might be those that follow less socially disruptive deaths: ' $[\mathrm{P}]$ utting the accent on the routine aspects of ritual conveniently conceals the agony of unexpected early deaths' (p. 13). This approach, he says, can 'mask the emotional force of bereavement by reducing funerary ritual to orderly routine' (p. 13). His work parallels Greek anthropologist Nadia Seremetakis' (1991) notion of ritualization-that is, more diffuse forms of ritualizing, which are less bounded within sacred time and space and more porous at the intersection between spaces. For Seremetakis it is 'what takes place within the flux and contingency of everyday events' that needs to be attended to (p. 47).

This distinction between the 'ritual event' and the 'process of ritualization' can be seen to mirror the contrast between professionals' concern with a funeral/disposal and the comprehensive temporal and spatial process that bereaved people may initiate. Such processes draw upon memory and demonstrate the reach forward of bereaved people's hope, action and indeed agency into a future populated by both the deceased and their survivors. The case study of Carol and Bill Devon below reveals, for example, a trajectory of care which had been sustained, unbroken, despite the death of Carol's father. The couple's narratives encompassed the previous life of the deceased, extending his social life through the locating and tending of his 'grave', and a sense of a future in which care was at issue. This case study demonstrates how individuals discover scope for innovation. Bourdieu's concept of the 'intentionless invention of regulated improvization' (1977, p. 79) helpfully reminds us that, particularly in a core narrative, broader cultural beliefs and values may be invoked in relation to apparently idiosyncratic personal innovations, constituting resources for the generation of accounts of strategic decision making that are marked by coherence. While her disposal and memorializing strategy was indeed innovative, Carol's motivated narrative asserted the moral nature of her responses to her father, both before and after his death, implicitly drawing upon the traditional cultural theme that women will provide hands-on care for elderly relatives, particularly men (cf. Dalley 1988).

\section{The Case of Carol and Bill Devon}

Now in her late 50s, Carol Devon was an only child brought up mainly by her father in social housing in a relatively poor area of Nottingham. She had retrieved her father's ashes from the crematorium and, together with her husband, Bill, described how they had cared for her father towards the end of his life. Well-being, we come to understand, is a relational issue; Carol describes managing her grief and achieving personal well-being, through attending to her father's well-being. Thus, she secured biographical continuity at a time of familial rupture.

Having relocated to a pensioners' complex opposite the Devons' home, Carol said of her father, 'if he wanted to go anywhere we used to take him with us didn't 


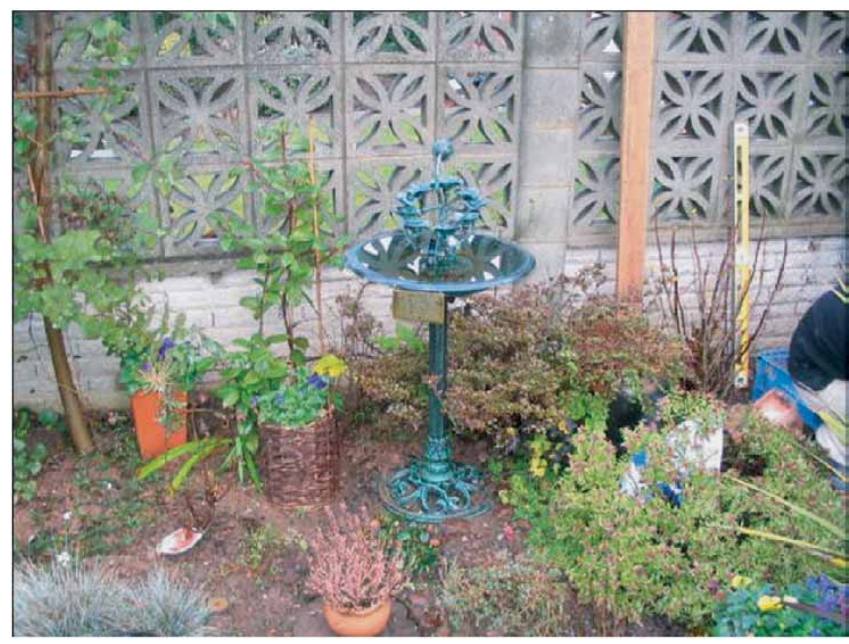

Figure 5 Bird Bath at Site of Ash Disposal in Back Garden.

we?' ... 'Loved it, and he loved to go to my daughter's, Tracy's, where he is now, he used to like to go down there, you know and sit in the garden, just sit.' Spatial proximity had been important and now the ashes rest in the daughter's garden, under a bird bath. Carol described how 'Tracy said "well I'm sure if he goes down here and we put the bird bath on top, he'll be alright, at least he'll be warm, he'll not get wet." 'Cos my dad was always cold, he had this condition where he was always cold.' She visits and talks to him regularly and said: 'where he is at Tracy's, the sun shines on him, the birds are there, have a drink of water, they can feed and everything and all the kids, I mean she has parties for the kids... Hallowe'en parties, everybody goes out there, the kids are running in and out, nobody's knocked it over and nobody's touched it, touch wood.' Her father's location at the centre of her family's life reflects his injunction that only his blood relatives should 'follow' his coffin in the first car. Refusing to have the cremated remains scattered at the crematorium, Carol and Bill reflected on them being blown over people's washing so that 'somebody [is] walking about with somebody on their back, 'til it's washed again.' Said humorously, Carol still stressed the desire to retain her father within the family: 'So I, I said no, I'm not leaving him, I didn't want to leave him up there, I just didn't want him up there, there was nobody up there who he knew, and to me he was my dad, and I wanted him with me.' Proximity therefore secured the well-being of the deceased and of the bereaved; Carol's only reason for not using her own garden being the likelihood of a future house move. As noted, in linking the notion of well-being with the concept of restoration, anthropologists have highlighted its broader environmental dimensions, both socially and materially. Here Carol's evocation of her family's chosen site of disposal highlights the social meaning of a space defined in terms of domestic and family usage.

Along with proximity, restitution was evoked as part of Carol's strategy. She saw her father's death as 'untimely', precipitated by the theft of his wallet, and its photos 
of his daughter and of himself in his army uniform. Afterwards his health and confidence declined and he no longer left the flat, dying suddenly. Carol found him in front of the television, dead, with his eyes open and saw his 'bad death' as the outcome of his victimization, rather than a 'good death', peacefully amidst his family (Bradbury 1993). However, she actively reinstated him, socially, placing him in his coffin in his blue blazer with his rosary, regimental badge and tie, and Union Jack socks given by his granddaughter. 'We dressed him', she said, expressing a powerful sense of agency in her choice of words. She recalled saying 'by gum it's a long while since I've seen him looking as good as this ... he looked just like my dad'. What she created, however, was not simply a representation of her father. His remains took on the status of the man she intended to continue looking after. So, for example, when two jumpers were mistakenly put among the clothes taken to the funeral directors, Carol told them: '[W]ell he always was cold, always on about his back being cold and, you know, always used to put plenty of clothes on, I says, so put him the two jumpers on, to keep his back warm, I said... and you know he looked a picture, he looked a picture, he did... he did, he looked lovely.'

This concept of warmth is a literal remedy for a medical condition her father suffered. Post mortem, it constituted a metaphor of caring that animated the cold sterility of the corpse and the ashes. Another Nottingham informant, Mrs Luke, used this concept, abhorring the idea of anyone walking on her husband's ashes. She said: ' $[\mathrm{H}] \mathrm{e}$ deserves more respect. While he's there [stored under the television], he's warm.' Continuing care of her father might appear to be simply comforting denial, yet via these processes of ritualization Carol ascribed a continuing social identity to her father using the materialities of the corpse, clothing, site of disposal and residual belongings. For her, grave-visiting helped with her grief, allowing her to feel that 'he'll never be gone'. Doing housework, she felt him watching, telling her that she was doing it wrong. While her Catholic faith provided limited help with her grief, her father's ashes and personal belongings proved more powerful: 'I think if you've got them nearer, you wouldn't grieve so much, you'd have your grieving but not for so long, and I think you'd have more peace of mind, I think so.'

Such strategies repair the rupture introduced by death, but Carol's 'improvizations' were also potentially 'regulated' (Bourdieu 1977, p. 79) by existing family practices. She had been in conflict with her mother-in-law since she believed her father would not like a Catholic ceremony. Refusing this type of funeral, she nonetheless did have masses said for him. In turn, Carol criticized her mother-in-law for leaving her husband's ashes at the crematorium. More attention had been devoted to her dog's ashes, Carol said, in that they were placed on the mantelpiece.

\section{Whose Well-being?}

To sum up, Carol Devon's narrative reveals the forcefully expressed belief system underpinning her choices. The events set in train by the theft of her father's wallet, an act which in her view 'killed him', had become a process of bricolage (Levi-Strauss 1976), the apparently ad hoc generation of creative ritualization through an assemblage of items from a diversity of cultural scripts. Carol selectively 
drew on traditions associated with longstanding community and religious practices-for example, personal care of the dead and Catholic masses. The technology that made cremation possible had, however, enabled the innovative response through which Carol, and her daughter, sustained the materiality of someone dead. It is upon these traditions and technologies that her father's continuing social identity was predicated. In her interview Carol presented an entirely rational and internally coherent account of how she made her choices, one that demonstrates how processes of innovation might, over time, yield to more 'systematic' recollections of what has been achieved. Within the conditions of modernist rationality, contrasting beliefs and practices that might in other circumstances be described as 'magical', 'supernatural', 'spiritual' or 'superstitious' are still asserted with persuasive coherence (Bennett \& Bennett 2000).

\section{Conclusion}

Our paper has demonstrated how ambiguous and contested ideas about well-being are apparent both within families and between professionals and lay people. In asserting her choice, Carol Devon opened up ways to manage grief-and secure well-being. Although this could have been achieved in the public arena of the crematorium grounds, the scope for small adjustments to disposal plans whenever the need is felt makes the enhancement of personal well-being an on-going possibility. The institutional requirement to accelerate or compress recovery strategies is circumvented by excluding administrative schedules for managing public sites of disposal. Within such arenas, professionals often adjudicate between mourners' competing wishes, while also managing their own well-being (Parsons 2003). The funeral director mentioned earlier acknowledged diversity, but quietly felt that 'excessive' memorialization could hinder well-being, prolonging grief; that people were better served by 'moving on'. Yet for Carol, and many other informants, keeping the dead socially alive through talking, visiting-with gifts and greeting cards-balanced feelings of grief with a powerful sense of agency and supported a framework of perception in which they could sustain the well-being of someone they cared for, and may have actively looked after in life. Insofar as the positive is narrated as off-setting the negative, a level of recovered well-being might be claimed; in that an individual 'chief mourner' assumes, and is given authority to decide about ash remains, the series of innovations described here can be seen as a template for a family's future disposal arrangements, for an evolving ritualization.

\section{Notes}

[1] To protect confidentiality, names and identifying details have been changed.

[2] We are grateful to the ESRC for their support for the study, 'Environments of Memory: Changing Rituals of Mourning and their Personal, Social and Emotional Implications'.

\section{References}

Andrews, F. M. \& Withey, S. B. (1976) Social Indicators of Well-being: Americans' Perceptions of Life Quality, Plenum Press, New York. 
Aristotle (1928) 'Topics' in The Works of Aristotle, Vol. I, Oxford University Press, London.

Bakewell, J. (2004) 'Burials, scattered ashes, memorials ... the new mantra of consumer choice now even applies to death', Guardian, 9 July.

Bennett, G. \& Bennett, K. M. (2000) 'The presence of the dead: an empirical study', Mortality, vol. 5, no. 2, pp. 139-157.

Bloch, M. \& Parry, J. (1982) Death and the Regeneration of Life, Cambridge University Press, Cambridge.

Bourdieu, P. (1977) Outline of a Theory of Practice, Cambridge University Press, Cambridge.

Bradburn, N. M. (1969) The Structure of Psychological Well Being, Aldine, Chicago.

Bradbury, M. (1993) 'Contemporary representations of "good" and "bad" death' in Death, Dying and Bereavement, eds D. Dickenson \& M. Johnson, Sage, London.

Bury, M. (2001) 'Illness narratives: fact or fiction?', Sociology of Health and Illness, vol. 23, no. 3, pp. 263-285.

Clifford, J. \& Marcus, G. E. (1986) Writing Culture. The Poetics and Politics of Ethnography, University of California Press, Berkeley and Los Angeles.

Craib, I. (1994) The Importance of Disappointment, Routledge, London.

Dalley, G. (1988) Ideologies of Caring, Macmillan, Basingstoke.

Davies, D. \& Shaw, A. (1995) Reusing Old Graves: A Report on Popular British Attitudes, Shaw \& Sons, Crayford, UK.

Francis, D., Kellaher, L. \& Neophytou, G. (2005) The Secret Cemetery, Berg, Oxford.

Hallam, E. \& Hockey, J. (2001) Death, Memory and Material Culture, Berg, Oxford.

Hansard (2004) House of Commons Index for Volume 417 (pts. 15, 45).

Hertz, R. (1960) Death and the Right Hand, Free Press, New York. Original work published 1907.

Hockey, J., Kellaher, L. \& Prendergast, D. (2005) Sustaining Kinship: Ritualisation and the Disposal of Human Ashes in the UK, Paper presented to the Department of Anthropology, London School of Economics.

Kellaher, L., Prendergast, D. \& Hockey, J. (2004) 'Resistance, renewal or reinvention: the removal of ashes from crematoria', Pharos International, vol. 70, no. 4, pp. 10-13.

Klass, D., Silverman, P. R. \& Nickman, S. L. (1996) Continuing Bonds: New Understandings of Grief, Taylor \& Francis, Washington.

Levi-Strauss, C. (1976) The Savage Mind, Weidenfeld \& Nicholson, London.

Parkes, C. M. (1972) Bereavement: Studies of Grief in Adult Life, Penguin, Harmondsworth.

Parsons, B. (2003) 'Conflict in the context of care: an examination of role conflict between the bereaved and the funeral director in the UK', Mortality, vol. 8, no. 1, pp. 67-87.

Radcliffe-Brown, A. R. (1968) 'Taboo' in Studies in Social and Cultural Anthropology, ed. J. Middleton, Thomas A. Crowell Co, New York.

Rosaldo, M. (1989) Culture and Truth: The Remaking of Social Analysis, Beacon Press, Boston.

Seremetakis, C. N. (1991) The Last Word: Women, Death and Divination in Inner Mani, University of Chicago Press, Chicago.

Van Gennep, A. ([1909] 1960) The Rites of Passage, University of Chicago Press, Chicago.

Walter, T. (1994) The Revival of Death, Routledge, London.

Walter, T. (1996) 'A new model of grief: bereavement and biography', Mortality, vol. 1, no. 1, pp. 7-26.

Walter, T. (1999) On Bereavement: The Culture of Grief, Open University Press, Buckingham.

Watson, J. (1982) 'Of flesh and bones: the management of death pollution in Cantonese society' in Death and the Regeneration of Life, eds M. Bloch \& J. Parry, Cambridge University Press, Cambridge.

West, H. R. (2004) An Introduction to Utilitarian Ethics, Cambridge University Press, Cambridge. World Health Organisation (1946) Constitution, WHO, New York. 